\title{
Quantitative Comparison of Linear Magnetic Gear with Different Types of PMs
}

\author{
Mu Chen ${ }^{1}$, K. T. Chau ${ }^{1}$, Wenlong $\mathrm{Li}^{1}$ and Chunhua $\mathrm{Liu}^{1}$ \\ ${ }^{1}$ Department of Electrical and Electronic Engineering, The University of Hong Kong, Hong Kong, China
}

\begin{abstract}
This paper presents a quantitative comparison between the non-rare-earth permanent magnet (PM) and rare-earth PM based linear magnetic gear. By using the finite element analysis, three linear magnetic gears adopting either the non-rare-earth PM or rare-earth PM are analyzed and discussed. Hence, the cost-effectiveness comparison among different types of PMs is conducted. The results indicate that the non-rare-earth $P M$ is preferred to the rare-earth PM for application to linear magnetic gears when cost-effectiveness is emphasized.
\end{abstract}

Index Terms - Linear magnetic gear, permanent magnet, finite element analysis, cost-effectiveness comparison.

\section{INTRODUCTION}

Magnetic gears [1]-[5] are becoming more and more attractive for various applications such as renewable power generation [6]-[10] and electric vehicle propulsion [11]-[15]. They can also be integrated into electric machines [16]-[20] to further improve the torque density [21]-[25]. Linear magnetic gears attract extensive attention because they offer remarkable advantages compared to traditional mechanical gears in terms of lower acoustic noise, physical isolation, higher transmission efficiency, reduced maintenance and improved reliability [26]-[30]. These high performances are mainly attributed to the application of permanent magnet (PM) materials. Nowadays the neodymium-ironborn $(\mathrm{NdFeB})$ and samarium-cobalt $(\mathrm{SmCo})$ are two common types of rare-earth magnets PMs whereas the aluminum-nickel-cobalt (Alnico) is a common type of non-rare-earth PM for application of magnetic gear [31][34]. Recently there is an increasing concern on the price and supply of rare-earth PMs although the rare-earth magnetic gears have better performance. Rare-earth PMs suffer from highly fluctuant supply and very expensive price which hinder their wide application. In order to overcome the above disadvantages of rare-earth PM materials, Alnico is paid more attention because of its abundant reserves and low price [35]-[39].

The purpose of this paper is to present a quantitative comparison between non-rare-earth PM and rare-earth PM based linear magnetic gears. In Section II the structure of the linear magnetic gear is introduced. In Section III, by using finite element method (FEM), the electromagnetic performances of linear magnetic gears

This work was supported and funded by the grant (Project Code: HKU710711E) from Hong Kong Research Grants Council, Hong Kong Special Administrative, China. adopting either non-rare-earth or rare-earth PM materials are analyzed and compared. In Section IV, the natural magnetic characteristics of the rare-earth and non-rareearth PMs are compared. In Section V, a costeffectiveness comparison among different types of PMs is carried out. At last, a conclusion will be drawn in Section VI.

\section{Structure of LineAR Magnetic GeAR}

Fig. 1 shows the configuration of linear magnetic gear which consists of the stationary ring, high-speed mover and low-speed mover. The stationary ring which sandwiched between the high-speed mover and the lowspeed mover takes the charge of modulating the magnetic field in airgaps. The stationary ring is manufactured of thin sheets of laminated ferromagnetic materials in order to build good magnetic paths as well as reduce eddy current. When the high-speed mover is pushed or pulled by the external force, the corresponding stationary rings modulate the flux produced by the PM pole-pairs on the low-speed mover and the flux produced by the PM polepairs on the high-speed mover. The mathematic relationships can be directly borrowed from its rotational counterpart [40]:

$$
\begin{gathered}
N_{s}=N_{l m}+N_{h m} \\
G_{r}=\frac{v_{h m}}{v_{l m}}
\end{gathered}
$$

where is $N_{s}$ the number of field-modulation ferromagnetic rings, $N_{l m}$ the number of active PM pole-pairs on the lowspeed mover, $N_{h m}$ is the number of active PM pole-pairs on the high-speed mover, $G_{r}$ is the gear ratio, $v_{h m}$ is the velocity of the high-speed mover, $\mathrm{v}_{l m}$ is the velocity of the low-speed mover. The detailed corresponding parameters of the linear magnetic gear are listed in Table I.

For a fair comparison, the three linear magnetic gears, which are installed with Alnico, $\mathrm{NdFeB}$ and $\mathrm{SmCo}$ respectively, adopt the same topology based on the following criteria:

- same speed and move distance of two movers;

- same yoke length in high and low speed movers;

- same field-modulation ferromagnetic ring;

- same gear ratio;

- same ferromagnetic materials used.

- same volume of PMs; 


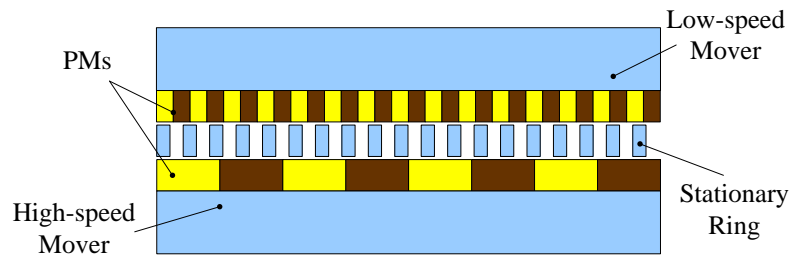

Fig. 1. Structure of linear magnetic gear

TABLE I. Key DATA OF LinEAR MAGNETIC GEAR

\begin{tabular}{|l|c|}
\hline Number of pole-pairs on high-speed mover & 4 \\
\hline Number of pole-pairs on low-speed mover & 15 \\
\hline Number of field-modulation ferromagnetic ring & 19 \\
\hline Length of high-speed mover yoke [mm] & 30 \\
\hline Length of low-speed mover yoke [mm] & 30 \\
\hline Thickness of PMs on high-speed mover [mm] & 10 \\
\hline Length of both airgaps [mm] & 1.0 \\
\hline $\begin{array}{l}\text { Thickness of field-modulation ferromagnetic } \\
\text { ring[mm] }\end{array}$ & 10 \\
\hline Thickness of PMs on low-speed mover [mm] & 10 \\
\hline
\end{tabular}

\section{Electromagnetic PERFormance COMPARISON}

By using finite element analysis, the electromagnetic performances of these three linear magnetic gears are evaluated and quantitatively compared. Firstly, the airgap flux density and force performances of the linear magnetic gear installed with Alnico are simulated as depicted in Fig. 2 and Fig. 3. Secondly, similar waveforms of the linear magnetic gear installed with NdFeB are shown in Fig. 4 and Fig. 5. Thirdly, similar waveforms of the linear magnetic gear installed with SmCo are obtained as shown in Fig. 6 and Fig. 7.

As expected, it is obvious that the rare-earth PMs based linear magnetic gears have better performance than the Alnico based magnetic gears. The steady forces developed at the high-speed mover and low-speed mover of the Alnico based linear magnetic gear are about $0.4 \mathrm{kN}$ and $1.5 \mathrm{kN}$ respectively, which are almost 17 times lower than the forces transmitted by the $\mathrm{NdFeB}$ based linear magnetic gear which exhibits about $6.7 \mathrm{kN}$ and $25 \mathrm{kN}$. Meanwhile, the SmCo based linear magnetic gear has nearly the same performance as the $\mathrm{NdFeB}$ based linear magnetic gear. Table II gives the data of the performance comparison.

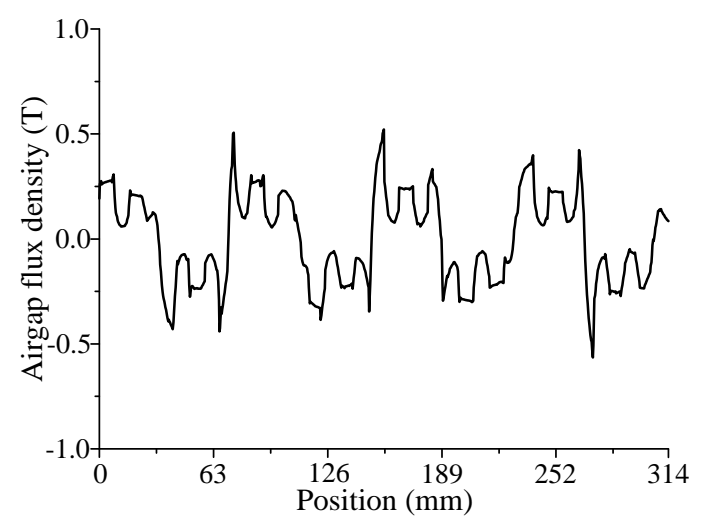

(a)

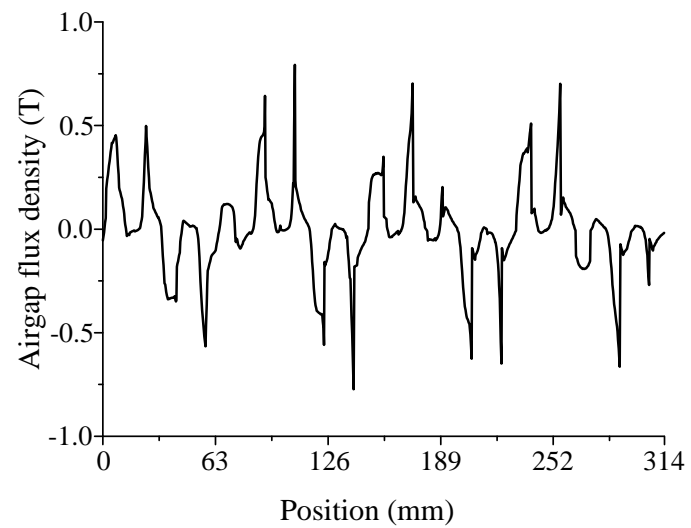

(b)

Fig.2 Airgap flux density of Alnico based linear magnetic gear (a) Airgap adjacent to the high-speed mover (b) Airgap adjacent to the low-speed mover

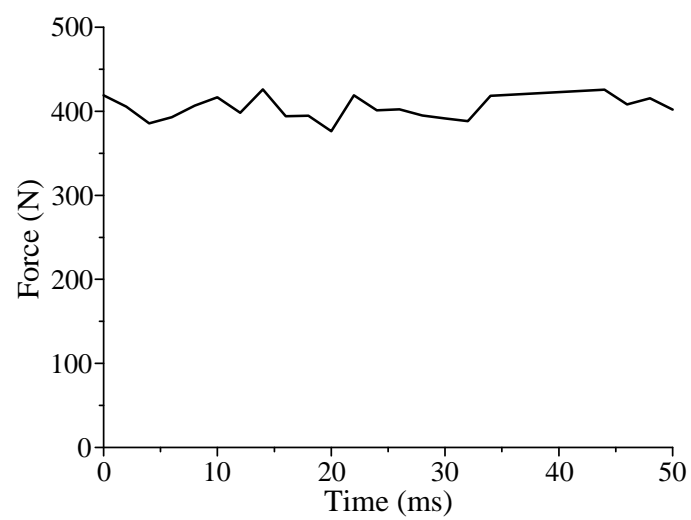

(a)

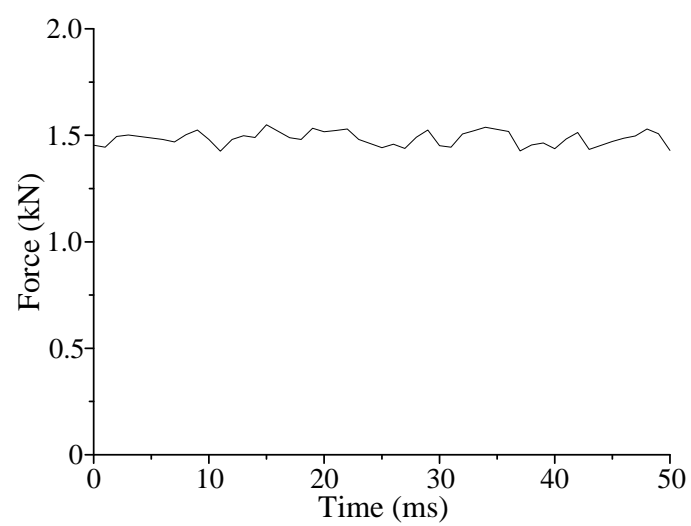

(b)

Fig.3 Force waveforms of Alnico based linear magnetic gear (a) high-speed mover (b) low-speed mover 


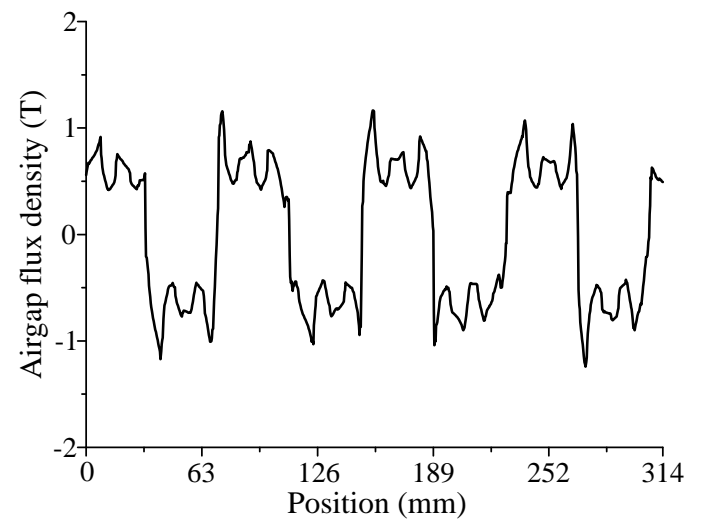

(a)

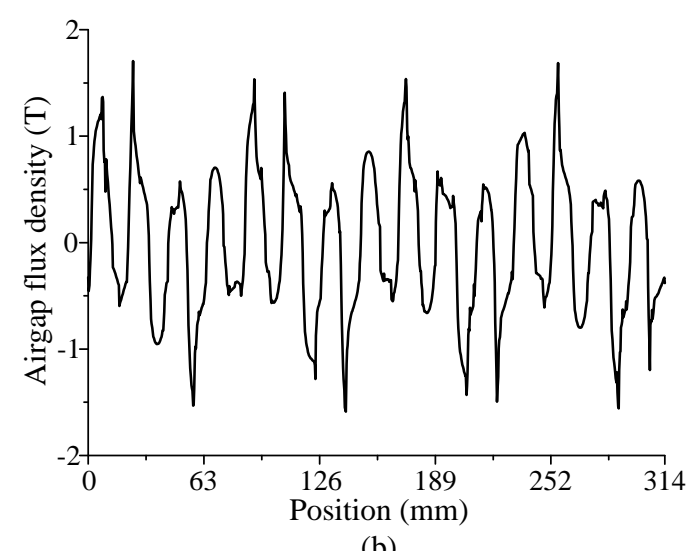

Fig.4 Airgap flux density of NdFeB based linear magnetic gear (a) Airgap adjacent to the high-speed mover (b) Airgap adjacent to the low-speed mover

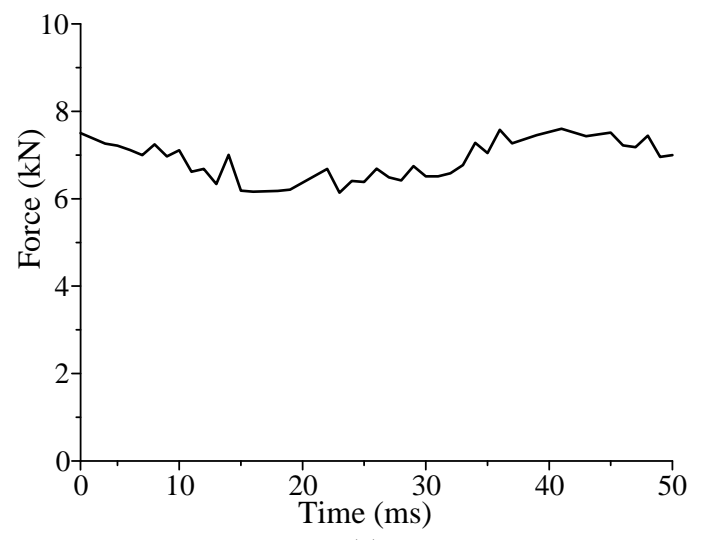

(a)

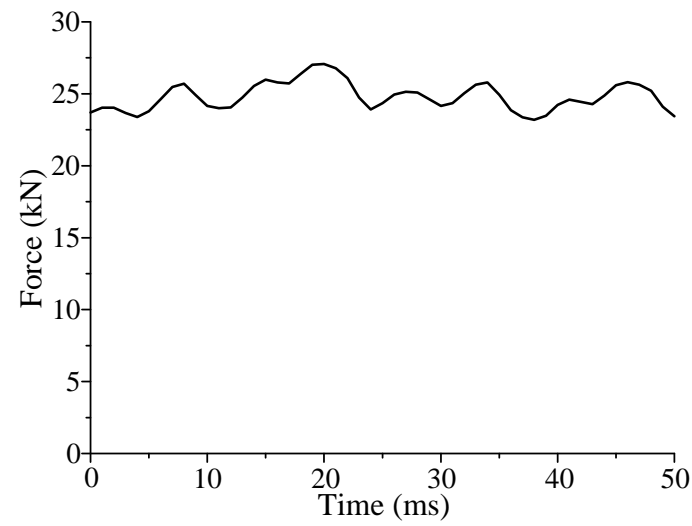

(b)

Fig.5 Force waveforms of $\mathrm{NdFeB}$ based linear magnetic gear (a) high-speed mover (b) low-speed mover

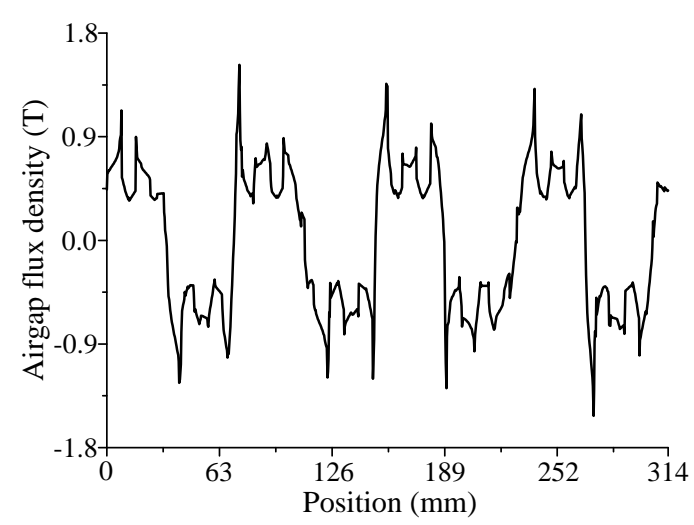

(a)

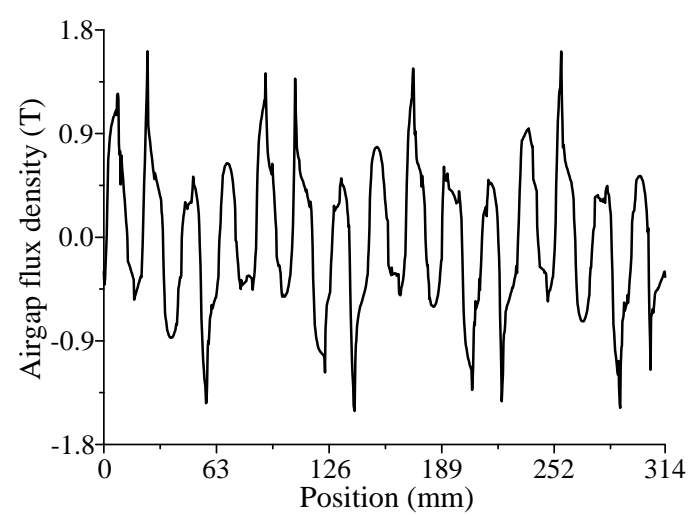

(b)

Fig.6 Airgap flux density of SmCo based linear magnetic gear (a) Airgap adjacent to the high-speed mover (b) Airgap adjacent to the low-speed mover 


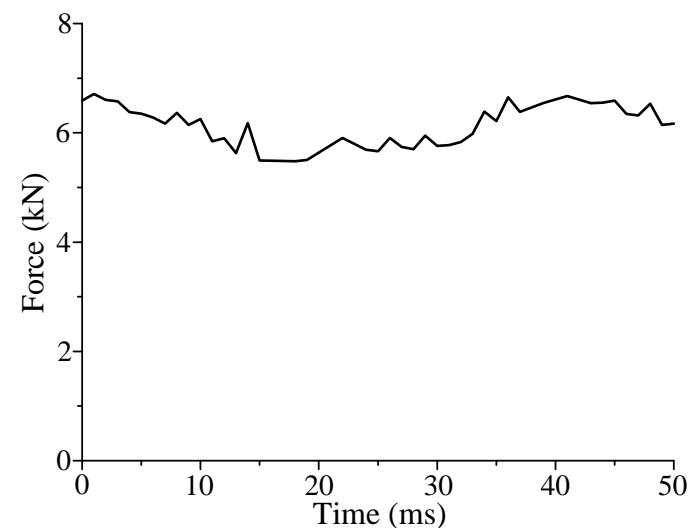

(a)

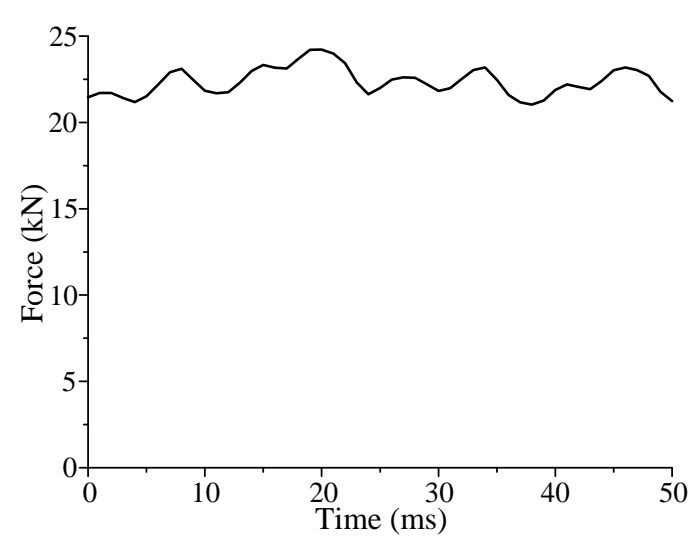

(b)

Fig.7 Force waveforms of SmCo based linear magnetic gear (a) high-speed mover (b) low-speed mover

TABLE II. LiNEAR MAGNETIC GEAR PERFORMANCE COMPARISON

\begin{tabular}{|l|c|c|c|}
\hline & Alnico & NdFeB & SmCo \\
\hline $\begin{array}{l}\text { High-speed mover } \\
\text { force[kN] }\end{array}$ & 0.4 & 6.7 & 6.2 \\
\hline $\begin{array}{l}\text { Low-speed mover } \\
\text { force[kN] }\end{array}$ & 1.5 & 25 & 23 \\
\hline
\end{tabular}

\section{RARE-EARTH AND NON-RARE-EARTH PMS COMPARISON}

The steady forces difference between the rare-earth and non-rare-earth elments mainly attributed to the natural magnetic characteristics of the PM materials used. Rare-earth PMs, which are developed in the 1970s and 80s, can produce significantly stronger magnetic field than the non-rare-earth PMs. The $\mathrm{NdFeB}$ and SmCo are two common types of rare-earth PMs which are widely adopted in industrial application.

The SmCo, which is the first member of rare-earth PMs, are made of an alloy of Sm, Co and other elements such as $\mathrm{Fe}$ and $\mathrm{Cu}$. Although it offers the merits of good temperature stability and high resistance to demagnetization, it is less attractive than the $\mathrm{NdFeB}$ because of its extremely high price and relatively weaker magnetic field strength.

The NdFeB, which is the most successful invention of the rare-earth $\mathrm{PMs}$, is an alloy of $\mathrm{Nd}, \mathrm{Fe}, \mathrm{B}$ and other elements such as $\mathrm{Re}, \mathrm{Al}$ and $\mathrm{Cu}$. It is the strongest and most affordable PM.

Although the rare-earth PMs have distinctive performance over other types of PMs, their fluctuant and expensive price as well as finite reserves hinder their further development for industrial application. The nonrare-earth PM Alnico, which is typically composed of $\mathrm{Al}$, $\mathrm{Ni}, \mathrm{Co}$ and other elements such as $\mathrm{Cu}, \mathrm{Ti}$ and $\mathrm{Fe}$, is a potential candidate to compute with the rare-earth PMs for general application because it has the prominent advantage of very high remnant flux density $\mathrm{B}_{\mathrm{r}}$ and very low raw material cost. Although the low coercivity $\mathrm{H}_{\mathrm{c}}$ makes it vulnerable to demagnetization, this demerit is invalid for magnetic gears or positively utilized because magnetic gears do not involve any armature current [36]. Table III quantitatively compare the natural magnetic characteristics among these three types of PMs.

TABle III. Magnet Material COMPaRisON
\begin{tabular}{|l|c|c|c|}
\hline & Alnico & NdFeB & SmCo \\
\hline $\mathrm{Hc}[\mathrm{A} / \mathrm{m}]$ & 275 & 2000 & 2000 \\
\hline $\mathrm{Br}[\mathrm{T}]$ & 1.4 & 1.4 & 1.1 \\
\hline $\mathrm{BH}_{\max }\left(\mathrm{kJ} / \mathrm{m}^{3}\right)$ & 88 & 440 & 440 \\
\hline
\end{tabular}

\section{COST-EFFECTIVENESS COMPARISON}

For a fair comparison, the raw material prices of these three types of PM materials are considered, while neglecting the product prices which are significantly influenced by many factors such as government policy as well as marketing strategy. Their raw material prices can readily be calculated according to the current market prices of individual elements and the chemical compositions of these three PMs. As China is one of the major producers of PMs, the prices of those elements are based on the Chinese material market as listed in Table IV.

\begin{tabular}{|c|c|c|c|}
\hline Element & Price(USD/kg) & Element & Price(USD/kg) \\
\hline $\mathrm{Sm}$ & 236.265 & $\mathrm{Al}$ & 2.363 \\
\hline $\mathrm{Nd}$ & 252.016 & $\mathrm{Fe}$ & 0.126 \\
\hline B & 3.938 & $\mathrm{Cu}$ & 8.506 \\
\hline $\mathrm{Ni}$ & 18.9011 & $\mathrm{Re}$ & 2362.65 \\
\hline $\mathrm{Co}$ & 35.125 & & \\
\hline
\end{tabular}

Consequently, the cost of three linear magnetic gears with different types of PMs can be easily calculated. The high-speed mover force is taken as the key indicator to reflect the cost-effectiveness. Table $\mathrm{V}$ summarizes the corresponding density, volume, composition, high-speed mover force and the resulting cost-effectiveness. The key is that all the three linear magnetic gears adopt the same volume of PMs $\left(6280 \mathrm{~cm}^{3}\right)$. Although the Alnico based linear magnetic gear possesses the lowest force output, it is most cost-effective. Namely, its cost-effectiveness is 
only 1.4134 N/USD which is $19 \%$ and $28 \%$ higher than that of the $\mathrm{NdFeB}$ one (1.1869 N/USD) and SmCo one (1.108 N/USD), respectively. Considering the abundant reserves of all required elements for Alnico, it is preferred to the $\mathrm{NdFeB}$ or $\mathrm{SmCo}$ for application to linear magnetic gears.

Furthermore, when the linear magnetic gear simply works as a speed reduction or force amplification device, it is free from accidental demagnetization due to armature reaction, which actually eliminates the key shortcoming of Alnico, namely low coercivity.

TABLE V. COST-EFFECTIVENESS COMPARISON

\begin{tabular}{|c|c|c|c|}
\hline & Alnico & $\mathrm{NdFeB}$ & $\mathrm{SmCo}$ \\
\hline $\begin{array}{l}\text { High-speed } \\
\text { mover force[kN] }\end{array}$ & 0.4 & 6.7 & 6.2 \\
\hline Volume $\left[\mathrm{cm}^{3}\right]$ & 6280 & 6280 & 6280 \\
\hline Composition & $\begin{array}{l}8 \%-12 \% \mathrm{Al} ; \\
15 \%-26 \% \mathrm{Ni} \\
5 \%-24 \% \mathrm{Co} \\
\mathrm{Fe} \text { (balance) }\end{array}$ & $\begin{array}{l}29 \%-32.5 \% \mathrm{Nd} \\
63.9 \%-68.6 \% \mathrm{Fe} \\
1.1 \%-1.2 \% \mathrm{~B} \\
0.6 \%-1.2 \% \mathrm{Re}\end{array}$ & $\begin{array}{l}35 \% \mathrm{Sm} ; \\
65 \% \mathrm{Co} ; \\
5 \% \mathrm{Fe}\end{array}$ \\
\hline Density $\left[\mathrm{g} / \mathrm{cm}^{3}\right]$ & 6.7 & 7.5 & 8.4 \\
\hline $\begin{array}{l}\text { Cost- } \\
\text { Effectiveness } \\
\text { Price[N/USD] }\end{array}$ & 1.4134 & 1.1869 & 1.108 \\
\hline
\end{tabular}

\section{CONCLUSION}

In this paper, the linear magnetic gears which are installed with either rare-earth or non-rare-earth PMs are discussed, with emphasis on performances, PM materials and cost-effectiveness comparison. Three linear magnetic gears individually adopt the Alnico, $\mathrm{NdFeB}, \mathrm{SmCo}$ are analyzed. Among the three different types of PMs, the $\mathrm{NdFeB}$ based linear magnetic gear offers the highest steady force over the others. Although the Alnico based linear magnetic gear owns the lowest force output, it offers the most cost-effective performance. Due to the abundant reserves and low raw material cost of Alnico as well as the high cost-effectiveness and free from armature field of the Alnico magnetic gear, the non-rare-earth magnetic gears are preferred to the rare-earth magnetic gears.

\section{ACKNOWLEDGMENT}

This work was supported and funded by the grant (Project Code: HKU710711E) from Hong Kong Research Grants Council, Hong Kong Special Administrative, China.

\section{REFERENCES}

[1] X. Liu, K. T. Chau, J. Z. Jiang and C. Yu, "Design and analysis of interior-magnet outer-rotor concentric magnetic gears," Journal of Applied Physics, Vol. 105. pp. 07F101:1-4, 2009.

[2] L. Jian and K. T. Chau, "Analytical calculation of magnetic field distribution in coaxial magnetic gears," Progress in Electromagnetics Research, Vol. 92, pp. 1-16, 2009.
[3] K. T. Chau, D. Zhang, J. Z. Jiang and L. Jian, "Transient analysis of coaxial magnetic gears using finite element comodeling," Journal of Applied Physics, Vol. 103, No. 7, pp. 07F101:1-3, 2008.

[4] L. Jian and K. T. Chau, "A coaxial magnetic gear with Halbach permanent magnet arrays," IEEE Transactions on Energy Conversion, Vol. 25, No. 2, pp. 319-328, 2010.

[5] T. Lubin, S. Mezani and A. Rezzoug, "Analytical Computation of the magnetic field distribution in a magnetic gear," IEEE Transactions on Magnetics, Vol. 46. No. 7, pp. 2611-2621, 2010.

[6] K. T. Chau, W. Li and C.H.T. Lee, "Challenges and opportunities of electric machines for renewable energy," Progress In Electromagnetics Research B, Vol. 42, pp. 4574, 2012.

[7] L. Jian, K. T. Chau, W. Li and J. Li, "A novel coaxial magnetic gear using bulk HTS for industrial application," IEEE Transactions on Applied Superconductivity, Vol. 20, No. 3, pp. 981-984, 2010.

[8] W. Li, K. T. Chau and J. Z. Jiang, "Application of linear magnetic gears for pseudo-direct-drive oceanic wave energy harvesting" IEEE Transactions on Magnets, Vol. 47, No. 10, pp. 2624-2627, 2011.

[9] L. Jian, K. T. Chau and J. Z. Jiang, "A magnetic-geared outer-rotor permanent-magnet brushless machine for wind power generation," IEEE Transactions on Industry Applications, Vol. 45, No. 3, pp. 954-962, 2009.

[10] P. O. Rasmussen, T. O. Andersen, F. T. Jorgensen and O. Nielsen, "Development of a high-performance magnetic gear," IEEE Transactions on Industry Applications, Vol. 41, No. 3, pp. 764-770, 2005.

[11] L. Jian and K. T. Chau, "Design and analysis of a magnetic-geared electronic-continuously variable transmission system using finite element method," Progress in Electromagnetics Research, Vol. 107, pp. 4761, 2010.

[12] L. Jian and K. T. Chau, "A novel electronic-continuously variable transmission propulsion system using coaxial magnetic gearing for hybrid electric vehicles," Journal of Asian Electric Vehicles, Vol. 7, No. 2, pp. 1291-1296, 2009.

[13] L. Jian and K. T. Chau, "Design and analysis of an integrated Halbach-magnetic-geared permanent-magnet motor for electric vehicles," Journal of Asian Electric Vehicles, Vol. 7, No. 1, pp. 1213-1219, 2009.

[14] C. Yu, K. T. Chau, X. Liu and J. Z. Jiang, "A fluxmnemonic permanent magnet brushless motor for electric vehicles," Journal of Applied Physics, Vol. 103, pp. 07F103:1-3, 2008.

[15] X. Zhu, L. Chen, L. Quan, Y. Sun, W. Hua and Z. Wang, "A new magnetic-planetary-geared permanent magnet brushless machine for hybrid electric vehicle," IEEE Transactions on Magnetics, Vol. 48, No. 11,pp. 4642-4645, 2012.

[16] X. Li, K. T. Chau, M. Cheng and W. Hua, "Comparison of magnetic-geared permanent-magnet machines," Progress in Electromagnetic Research, Vol. 133, pp. 177-198, 2013.

[17] K. T. Chau, D. Zhang, J. Z. Jiang, C. Liu and Y. J. Zhang, "Design of a magnetic-geared outer-rotor permanentmagnet brushless motor for electric vehicle," IEEE Transactions on Magnets, Vol. 43, No. 6, pp. 2504-2506.

[18] C. Liu, K. T. Chau and Z. Zhang, "Novel design of doublestator single-rotor magnetic-geared machines," IEEE Transactions on Magnetics, Vol. 48, No. 11, pp. 41804183, 2012.

[19] W. Li and K. T. Chau, "A linear magnetic-geared freepiston generator for range-extended electric vehicles," 
Journal of Asian Electric Vehicles, Vol. 8, No. 1, pp. 1345$1349,2010$.

[20] S. Niu, S. L. Ho and W. N. Fu, "Performance analysis of a novel magnetic-geared tubular linear permanent magnet machine," IEEE Transactions on Magnetics, Vol. 47, No. 10, pp. 3598-3601, 2011.

[21] S. Mezani, K. Atallah and D. Howe, "A high-performance axial-field magnetic gear," Journal of Applied Physics, Vol. 99, pp. 08R303:1-3, 2006.

[22] K. Atallah, S. Calverley, R. Clark, J. Rens and D. Howe, "A new PM machine topology for low-speed, high torque drives," Proceedings of the 2008 International Conference on Electrical Machines, pp. 1-4, 2008.

[23] K. Atallah, S. D. Calverley and D. Howe, "Design, analysis and realization of a high-performance magnetic gear," IEE Proceedings-Electric Power Applicaotin, Vol. 151, No. 2, 135-143, 2004.

[24] J. Rens, K. Atallah, S. Calverley and D. Howe, "A novel magnetic harmonic gear," IEEE Transactions on Industry Applications, Vol. 46, No. 1, pp. 206-212, 2010.

[25] K. Atallah J. Wang, S. Calverley and S. Duggan, "Design and operation of a magnetic continuously variable transmission," IEEE Transactions on Industry Applications, Vol. 48, No. 4, 1288-1295, 2012.

[26] W. Li, K. T. Chau and J. Li, "Simulation of a tubular linear magnetic gear using HTS bulks for field modulation," IEEE Transactions on Applied on Superconductivity, Vol. 21, No. 3, pp.1167-1170, 2011.

[27] W. Li and K.T. Chau, "Analytical field calculation for linear tubular magnetic gears using equivalent anisotropic magnetic permeability," Progress In Electromagnetics Research, Vol. 127, pp. 155-171, 2012.

[28] K. Atallah, J. Wang and D. Howe, "A high-performance linear magnetic gear," Journal of Applied Physics, Vol. 97, pp. 10N516:1-3, 2005.

[29] E. Gouda, S. Mezani, L. Baghli and A. Rezzoug, "Comparative study between mechanical and magnetic planetary gears," IEEE Transactions on Magnetics, Vol. 47, No. 2, pp. 439-450, 2011.

[30] R. Holehouse, K. Atallah and J. Wang, "Design and realization of a linear magnetic gear," IEEE Transactions on Magnetics, Vol. 47, No. 10, pp. 4171-4174, 2011.

[31] S. Kikuchi, and K. Tsurumoto, "Design and characteristics of a new magnetic worm gear using permanent magnet," IEEE Transactions on Magnetics, Vol. 29, No. 6, 29232925, 1993.

[32] S. Kikuchi, and K. Tsurumoto, "Trial construction of a new magnetic skew gear using permanent magnet," IEEE Transactions on Magnetics, Vol. 30, No. 6, 47674769,1994

[33] Ikuta, K., S. Makita, and S. Arimoto, Non-contact magnetic gear for micro transmission mechanism, Proc. IEEE Conf. on Micro Electro Mechanical Systems, pp. 125-130, 1991.

[34] Huang C. C., M. C. Tsai, D. G. Dorrell, and B. J. Li, Development of a magnetic planetary gearbox, IEEE Transaction on Magnetics, Vol. 44, No. 3, 403-412, 2008.

[35] M. Chen, K. T. Chau, W. Li and C. Liu, "Development of non-rare-earth magnetic gears for electric vehicles," Journal of Asian Electric Vehicles, Vol. 10, No. 2, pp. 1607-1613, 2012.

[36] C. Yu, K. T. Chau and J. Z. Jiang, "A flux-mnemonic permanent magnet brushless machine for wind power generation," Journal of Applied Physics, Vol. 105, No. 7, pp. 07F114: 1-3, 2009.

[37] W. Li, K. T. Chau, Y. Gong, J. Z. Jiang and F. Li, "A new flux-mnemonic dual-magnet brushless machine," IEEE
Transactions on Magnetics, Vol. 47, No. 10, pp. 42234226.

[38] F. Li, K. T. Chau, C. Liu and Z. Zhang, "Design principles of permanent magnet dual-memory machines," IEEE Transactions on Magnetics, Vol. 48, No. 11, pp. 32343237, 2012.

[39] F. Li, K. T. Chau, C. Liu, J. Z. Jiang and Y. Wong, "Design and analysis of magnet proportioning for dualmemory machines," IEEE Transactions on Applied Superconductivity, Vol. 22, No. 3, pp. 4905404-4905407, 2012.

[40] K. Atallah and D. Howe, "A novel high-performance magnetic gear," IEEE Transactions on Magnetics, Vol. 37, No. 4, 2844-2846, 2001. 